\title{
Commentary: Minimally invasive direct coronary artery bypass: Reawakening of a sleeping beauty?
}

\author{
Theodor Fischlein, MD
}

\author{
From the Department of Cardiac Surgery, Cardiovascular Center, Klinikum Nürnberg, Paracelsus Medical Uni- \\ versity, Nuremberg, Germany. \\ Disclosures: Author has nothing to disclose with regard to commercial support. \\ Received for publication Nov 22, 2018; accepted for publication Nov 26, 2018; available ahead of print Jan 7 , \\ 2019. \\ Address for reprints: Theodor Fischlein, MD, Department of Cardiac Surgery, Klinikum Nürnberg, Breslauer- \\ strasse 201-90471, Nuremberg, Germany (E-mail: theodor.fischlein@klinikum-nuernberg.de). \\ J Thorac Cardiovasc Surg 2019;158:139-40 \\ $0022-5223 / \$ 36.00$ \\ Copyright (c) 2018 by The American Association for Thoracic Surgery \\ https://doi.org/10.1016/j.jtcvs.2018.11.081
}

Minimally invasive direct coronary artery bypass (MIDCAB) grafting was introduced in the mid-1990s for revascularization of the left anterior descending coronary artery (LAD) as an off-pump procedure through a left anterior lateral minithoracotomy. ${ }^{1}$ Despite an initial hype or enthusiasm surrounding this technique, especially for patients with complex LAD lesions that might not be ideal for stenting, the acceptance and interest in this revascularization option declined, and it was subsequently performed only in some dedicated centers. The reasons for this are numerous: MIDCAB surgery is more technically complex in terms of learning curve, and obtaining an adequate length of the left internal thoracic artery through a small thoracotomy, particularly in obese patients, can be challenging. An intramyocardial course of the LAD in combination with extensive epimyocardial fat or calcification easily turns this technique into a bold venture. In addition, pain can be a significant issue during the first postoperative days because of the required rib spreading. On the other hand, MIDCAB surgery is less invasive than conventional sternotomy procedures, avoids any aortic manipulation, and could result in faster mobilization and recovery for patients.

In this issue of the Journal, Repossini and colleagues ${ }^{2}$ describe a prospective follow-up study of the outcomes of 20-year experience with 1060 patients who underwent grafting with the MIDCAB method. The patient cohort was divided into two therapeutic groups, one with isolated LAD disease unsuited to percutaneous coronary intervention (PCI) and one with multivessel disease with functional incomplete revascularization but optimal medical treatment or hybrid coronary revascularization (HCR) with stenting. These were mostly patients with coronary artery disease and severe comorbidities contraindicating sternotomy or cardiopulmonary bypass. That means that patients had a left internal thoracic artery to LAD MIDCAB procedure, and all other vessels were treated with PCI before

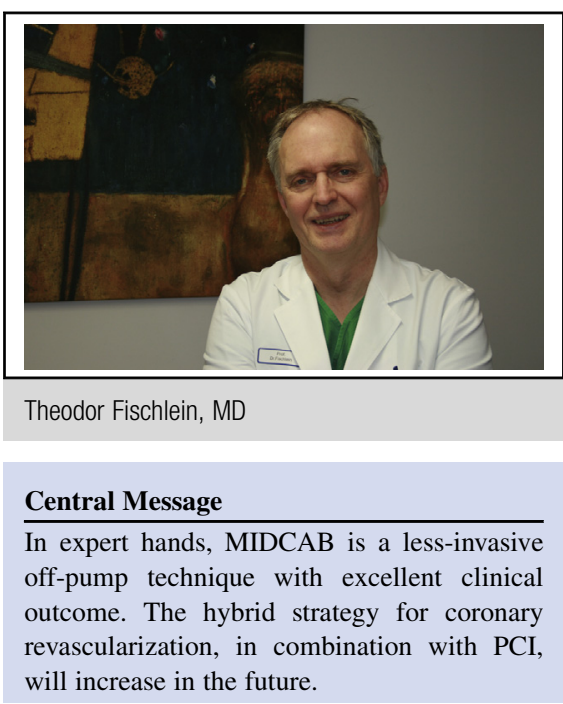

See Article page 127.

or after surgical treatment. Repossini and colleagues ${ }^{2}$ state that MIDCAB can be safely performed in both groups, with excellent short- and long-term survivals in combination with freedom from mature adverse events. Although publications of long-term results after MIDCAB procedures are rare, some studies have recently shown similar results. ${ }^{3}$ Although some concerns have been raised regarding the quality of the anastomosis relative to full sternotomy procedures, shorter length of hospital stay, lower incidence of wound infections, and shorter median time to return to full activity were noted in the MIDCAB group of Florisson and associates. ${ }^{4}$ Even in comparison with PCI, minimally invasive surgical procedures resulted in a better outcome. At 10 years, PCI with drug-eluting stent was associated with a 2.19-fold increased risk of late death, a 2.0-fold increased risk of repeat revascularization, and a 2.14fold increased risk of the composite of death and repeat revascularization relative to MIDCAB in the study of Benedetto and colleagues. ${ }^{5}$ During the last several years, HCR for the treatment of multivessel coronary artery disease has emerged as an alternative option. High-risk patients with multiple comorbidities are mostly appropriate for this technique and could benefit most from avoiding a sternotomy. ${ }^{6}$ In addition, patients with a complex LAD lesion not suitable for stenting, along with lesions in other coronary arteries that are easily stented, are ideal candidates for HCR. They benefit from the longevity of a thoracic artery bypass anastomosed to the LAD with the MIDCAB 
technique, usually performed before the combined PCI treatment.

Repossini and colleagues ${ }^{2}$ are to be congratulated for their excellent results and the routine use of the MIDCAB technique. The continuous application of this technique is a kind of guarantee of good clinical performance and outcome. Repossini has performed MIDCAB procedures continuously almost during his whole surgical career, which may be the crucial factor for a safe and successful clinical outcome. Our patients are demanding less-invasive surgical procedures, so more surgeons should awaken interest and include MIDCAB in their daily practice. Because interdisciplinary cooperation with cardiologists and interventionalists is growing, HCR has the potential to become a more important option for coronary revascularization. Of course, evidence from more multicenter and randomized studies is needed, but this sleeping beauty seems to be worthwhile to keep alive to offer the best individual treatment for our patients.

\section{References}

1. Calafiore AM, Giammarco GD, Teodori G, Bosco G, D'Annunzio E, Barsotti A, et al. Left anterior descending coronary artery grafting via left anterior small thoracotomy without cardiopulmonary bypass. Ann Thorac Surg. 1996;6:1658-63; discussion 1664-5.

2. Repossini A, Di Bacco L, Nicoli F, Passaretti B, Stara A, Jonida B, et al. Minimally invasive coronary artery bypass: twenty-year experience. J Thorac Cardiovasc Surg. 2019;158:127-38.e1.

3. Seo DH, Kim JS, Park KH, Lim C, Chung SR, Kim DJ. Mid-term results of minimally invasive direct coronary artery bypass grafting. Korean J Thorac Cardiovasc Surg. 2018;51:8-14.

4. Florisson DS, DeBono JA, Davies RA, Newcomb AE. Does minimally invasive coronary artery bypass improve outcomes compared to off-pump coronary bypass via sternotomy in patients undergoing coronary artery bypass grafting? Interact Cardiovasc Thorac Surg. 2018;27:357-64.

5. Benedetto U, Raja SG, Soliman RF, Albanese A, Jothidasan A, Ilsley CD, et al; Harefield Cardiac Outcomes Research Group. Minimally invasive direct coronary artery bypass improves late survival compared with drug-eluting stents in isolated proximal left anterior descending artery disease: a 10-year follow-up, singlecenter, propensity score analysis. J Thorac Cardiovasc Surg. 2014;148:1316-22. Erratum in J Thorac Cardiovasc Surg. 2015;149:947.

6. Puskas JD, Halkos ME, DeRose JJ, Bagiella E, Miller MA, Overbey J, et al. Hybrid coronary revascularization for the treatment of multivessel coronary disease: a multicenter observational study. J Am Coll Cardiol. 2016;68: 356-65. 